\title{
Analisis Perbandingan Kinerja Algoritma Naïve Bayes, Decision Tree- J48 dan Lazy-IBK
}

\section{Indra Rukmana*, Arvin Rasheda, Faiz Fathulhuda, Muh Rizky Cahyadi, Fitriyani}

\author{
Teknologi Informasi, Teknik Informatika, ARS University, Bandung, Indonesia \\ Email: 1,*17180056@ ars.ac.id, ${ }^{2} 17180093 @$ ars.ac.id, ${ }^{3} 17180005 @$ ars.ac.id, ${ }^{4} 17180099 @$ ars.ac.id, ${ }^{5}$ fitriyani@ars.ac.id \\ Email Penulis Korespondensi: 17180056@ars.ac.id
}

\begin{abstract}
Abstrak-Penetilian ini di khususkan untuk mengetahui kinerja algoritma klasifikasi yaitu Naïve Bayes, Decision Tree-J48 dan Lazy-IBK. Kecepatan dan persentase akurasi pada penelitian ini menjadi tolak ukur kinerja pada algoritma. Penelitian ini menggunakan dataset Breast Cancer dan Thoracic Surgery Data yang di unduh pada website UCI Machine Learning Repository. Menggunakan bantuan software Weka Versi 3.8.5 untuk mengetahui pengujian kinerja algoritma klasifikasi tersebut. Hasil menunjukan bahwa algoritma Decision Tree J-48 memiliki akurasi terbaik yaitu $75.6 \%$ pada mode tes crossvalidation untuk dataset Breast Cancer dan $84.5 \%$ pada dataset Thoracic Surgery.
\end{abstract}

Kata Kunci: Naïve Bayes; Decision Tree-J48; Lazy-IBK; UCI Machine Learning

Abstract-This research is focused on knowing the performance of the classification algorithms, namely Naïve Bayes, Decision Tree-J48 and K-Nearest Neighbor. The speed and the percentage of accuracy in this study are the benchmarks for the performance of the algorithm. This study uses the Breast Cancer and Thoracic Surgery dataset, which is downloaded on the UCI Machine Learning Repository website. Using the help of Weka software Version 3.8.5 to find out the classification algorithm testing. The results show that the J-48 Decision Tree algorithm has the best accuracy, namely $75.6 \%$ in the crossvalidation test mode for the Breast Cancer dataset and $84.5 \%$ for the Thoracic Surgery dataset.

Keywords: Naïve Bayes; Decision Tree-J48; Lazy-IBK; UCI Machine Learning

\section{PENDAHULUAN}

Kanker adalah penyakit yang terjadi akibat pertumbuhan sel-sel abnormal yang tidak terkendali. Kanker payudara adalah kanker yang paling umum pada wanita. WHO mengestimasikan bahwa 84 juta orang meninggal akibat kanker dalam rentang waktu 2005-2015. Survei yang dilakukan WHO tersebut menyatakan bahwa 8 sampai 9 persen wanita mengalami kanker payudara. Hal itu membuat kanker payudara sebagai jenis kanker yang paling banyak ditemui pada wanita setelah kanker leher rahim [1]. Hal tersebut didukung data statistik American Cancer Society yang menunjukan bahwa kanker payudara menempati urutan pertama dengan jumlah kasus terbanyak dari seluruh jenis kasus tumor ganas (kanker) di seluruh dunia [2].

Operasi toraks adalah cabang ilmu kedokteran yang mempelajari diagnosis dan tindakan untuk gangguan kesehatan yang disebabkan oleh penyakit atau cedera pada kerongkongan, paru-paru, dan organ tubuh lain yang ada di dada. Salah satu penyakit yang paling sering ditangani dengan operasi toraks adalah kanker paru-paru[3] Menurut World Health Organization (WHO), kanker paru merupakan penyebab utama kematian utama dalam kelompok kanker. Penyebab paling umum kanker paru adalah paparan dalam jangka waktu yang lama terhadap asap tembakau [4].

Pada masa yang lalu, analisis data mining harus dilakukan secara manual - sebuah cara yang sangat tidak praktis tentunya. Sekarang ini dengan kekuatan sebuah komputer yang cukup modern, data yang sama dapat diinterpretasi dan dijelaskan dalam kurun waktu yang sangat efisien dengan menggunakan sejumlah teknik data mining yang bervariasi dan terotomatisasi.

Data mining adalah suatu proses ekstraksi atau penggalian data yang belum diketahui sebelumnya, namun dapat dipahami dan berguna dari database yang besar serta digunakan untuk membuat suatu keputusan bisnis yang sangat penting. Data mining biasa juga disebut dengan "Data atau knowledge discovery" atau menemukan pola tersembunyi pada data. Data mining adalah proses dari menganalisa data dari prespektif yang berbeda dan menyimpulkannya ke dalam informasi yang berguna [5].

Data mining didefinisikan sebagai proses mengekstrak atau menambang pengetahuan yang dibutuhkan dari sejumlah data besar. Pada prosesnya data mining akan mengekstrak informasi yang berharga dengan cara menganalisis adanya pola-pola ataupun hubungan keterkaitan tertentu dari data-data yang berukuran besar. Data mining berkaitan dengan bidang ilmu-ilmu lain, seperti Database System, Data Warehousing, Statistic, Machine Learning, Information Retrieval, dan Komputasi Tingkat Tinggi. Selain itu data mining didukung oleh ilmu lain seperti Neural Network, Pengenalan Pola, Spatial Data Analysis, Image Database, Signal Processing [6].

Klasifikasi termasuk ke dalam supervised learning karena menggunakan sekumpulan data untuk dianalisis terlebih dahulu, kemudian pola dari hasil analisis tersebut digunakan untuk engklasifikasian data uji. Proses klasifikasi data terdiri dari pembelajaran dan klasifikasi. Pada pembelajaran data training dianalisis menggunakan algoritma klasifikasi, selanjutnya pada klasifikasi digunakan data testing untuk memastikan tingkat akurasi dari rule klasifikasi yang digunakan. Teknik klasifikasi dibagi menjadi lima kategori berdasarkan perbedaan konsep matematika, yaitu berbasis statistik, berbasis jarak, berbasis pohon keputusan, berbasis jaringan syaraf, dan berbasis rule [7]. 
Sebagai suatu rangkaian proses, data mining mempunyai beberapa pengolahan data, yaitu adalah klasifikasi. Tujuan dari penelitian ini adalah untuk mengetahui kinerja algoritma klasifikasi sehingga dapat memprediksi perbandingan kinerja dari 3 algoritma tersebut yang mana memiliki akurasi terbaik. Beberapa algoritma yang akan digunakan adalah Nä̈ve Bayes, Lazy-IBK, dan Decision Tree-J48. Menggunakan software bantuan yaitu Weka Versi 3.8.5 sebagai tolak ukur untuk mengetahui kinerja pada algoritma tersebut.

Pada penelitian yang dilakukan oleh Abdul Rahman Kadafi ditahun 2018 membuktikan bahwa algoritma Nä̈ve Bayes memiliki algoritma yang paling baik dibandingkan algoritma yang lainnya[8] Selanjutnya dari penelitian lain dilakukan oleh Devinta dkk pada tahun 2020 menunjukan bahwa algoritma Naïve Bayes menjadi yang paling tinggi diantara algoritma yang lain dengan nilai akurasi sebesar 0.94[9]. Yang ketiga yaitu penelitian dilakukan oleh Devi Yunita di tahun 2017 membuktikan bahwa Algoritma K-Nearest Neighbor (K-NN) memiliki nilai akurasi yang lebih baik daripada Decision Tree[10]. Selanjutnya penelitian yang dilakukan oleh Ardiansyah dkk pada tahun 2018 menunjukan bahwa Nä̈ve Bayes merupakan algoritma dengan performa terbaik, dan hasil tertinggi akurasi didapatkan oleh algoritma K-NN[11]. Penelitian terakhir yang dilakukan oleh Pandito dan Dian pada tahun 2019 membuktikan bahwa algoritma Nä̈ve Bayes dengan akurasi 84.07\% mengungguli algoritmaalgoritma lainnya [12].

Dari kelima penelitan tersebut, membuktikan bahwa algoritma Nä̈ve Bayes dan KNN memiliki tingkat akurasi dan kinerja yang lebih unggul dibandingkan dengan algoritma klasifikasi lainnya. Namun penelitian ini akan membuktikan apakah hasil yang didapatkan sama dengan penelitian tersebut.

\section{METODOLOGI PENELITIAN}

\subsection{Tahapan Penelitian}

Tahapan penelitian yang dilakukan pada penelitian ini dapat dilihat pada gambar 1.

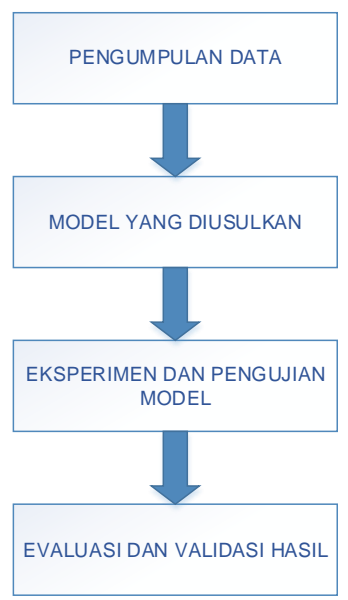

Gambar 1. Tahapan Penelitian

Pada gambar 1, tahapan yang dilakukan pada penelitian ini adalah sebagai berikut :

1) Pengumpulan data

Dataset dapat di unduh dari website UCI Repository dengan url:

https://archive.ics.uci.edu/ml/datasets/Thoracic+Surgery+Data

https://archive.ics.uci.edu/ml/datasets/Breast+Cancer

2) Model yang diusulkan

Model yang diusulkan dalam penelitian ini yaitu menggunakan beberapa algoritma diantaranya Nä̈ve Bayes, Decision Tree-J48, dan Lazy-Ibk dan mode test yang digunakan adalah cross-validation test

3) Eksperimen dan Pengujian Model

Eksperimen dan Pengujian Model dilakukan dalam beberapa cara yaitu:

a) Mempersiapkan dataset

b) Merubah file tipe .data ke .csv agar mempermudah pengolahan

c) Melakukan uji tes terhadap file .csv

d) Melakukan tes terhadap file .arff

4) Evaluasi dan Validasi Hasil

Pada saat eksperimen akan menghasilkan output kinerja dari beberapa algoritma dan akan menghasilkan akurasi terbaik pada kinerja algoritma

Hasil yang tertera pada proses Classifier output setelah melalui proses pembangunan model akan dicatat dan dari pencatatan tersebut akan dbandingkan nilainya, sehingga dapat diketahui algoritma mana yang kinerjanya 
paling baik. Parameter yang digunakan untuk membandingkan kinerja dari beberapa algoritma klasifikasi tersebut adalah:

1) Test Mode: Mendefinisikan mode tes yang digunakan cross-validation test

2) Time to build model: merupakan istilah untuk menerangkan beberapa waktu yang dibutuhkan untuk membangun model klasifikasi untuk masing-masing algoritma

3) Correctly classified instances: berapa banyak baris data yang terklasifikasikan dengan benar.

4) Incorrectly classified intances: berapa banyak baris data yang terklasifikasikan tidak benar

\subsection{Decision Tree}

Decision Tree adalah struktur flowchart yang menyerupai Tree (pohon), dimana setiap simpul internal menandakan suatu tes pada atribut, setiap cabang merepresentasikan hasil tes, dan simpul daun merepresentasikan kelas atau distribusi kelas. Alur pada Decision Tree di telusuri dari simpul akar ke simpul daun yang memegang prediksi [13].

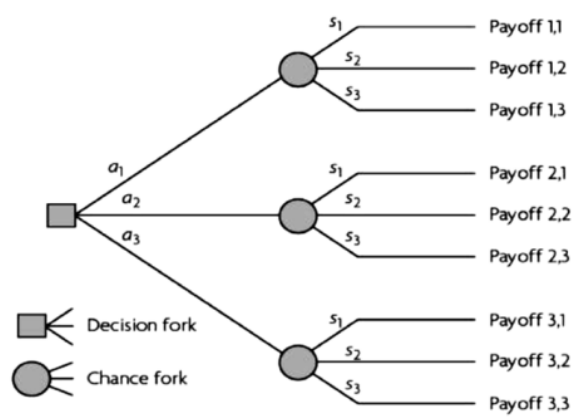

Gambar 2. Decision Tree Secara umum

Algoritma ini digunakan untuk menguji setiap atribut-atribut yang memungkinkan untuk menghasilkan keputusan-keputusan baru sampai pada akhirnya menemukan keputusan yang tepat (leaf node). Pohon keputusan berfungsi untuk mengeksplorasi data, menemukan hubungan tersembunyi antara variabel dependen dan independen[14].

\subsection{Nä̈ve Bayes Classifier}

Naïve Bayes sendiri merupakan suatu metode klasifikasi pada kategori supervised learning, dimana pada tahap naïve bayes dibutuhkan dataset awal untuk melakukan pelatihan untuk menghasilkan suatu keputusan. Pelatihan tersebut menentukan nilai probabilitas sebagai pemberian bobot untuk setiap parameter. Metode naïve bayes ini merupakan metoda klasifikasi yang cukup mudah dan akurat untuk diterapkan pada suatu permasalahan klasifikasi atau data mining[15]. Persamaan dari teorema Bayes adalah:

$$
(A \mid B) \frac{(P(B \mid A) \cdot P(A)}{P(B)}
$$

Keterangan:

B

A

$\mathrm{P}(\mathrm{A})$

$\mathrm{P}(\mathrm{B})$

$\mathrm{P}(\mathrm{B} \mid \mathrm{A})$

$\mathrm{P}(\mathrm{A} \mid \mathrm{B})$
: Data dengan kelas yang belum diketahui

: Hipotesa data B merupakan suatu kelas spesifik.

: Probabilitas hipotesa A (prior probability / probabilitas awal).

: Probabilitas B

: Probabilitas hipotesa B berdasarkan kondisi A

: Probabilitas hipotesa A berdasarkan kondisi B (Posterior probability probabilitas akhir)

\subsection{Lazy-IBK}

Lazy -IBK atau dikenal dengan algoritma K-Nearest Neighbor (K-NN) adalah pendekatan untuk mencari kasus dengan menghitung kedekatan antara kasus baru dengan kasus lama. Jumlah data/tetangga terdekat ditentukan oleh user yang dinyatakan dengan $k$ [16]. Algoritma K-Nearest Neighbor (K-NN) adalah salah satu algoritma paling sederhana untuk memecahkan masalah klasifikasi dengan hasil yang signifikan[17].

\section{HASIL DAN PEMBAHASAN}

\subsection{Dataset}

Untuk Penelitian ini menggunakan dua buah dataset yang telah di unduh pada website UCI Machine Learning Repository, dalam bentuk format .data dan diubah menjadi file .csv (microsoft excel). Dua dataset tersebut adalah 
ISSN 2614-5278 (media cetak), ISSN 2548-8368 (media online)

Available Online at https://ejurnal.stmik-budidarma.ac.id/index.php/mib DOI 10.30865/mib.v5i3.3055

Breast Cancer dan Thoracic Surgery. Kedua dataset tersebut berisi tentang Kanker Payudara dan Bedah Dada. Detail keterangan dari masing-masing dataset tertera pada tabel 1.

Tabel 1. Informasi dataset

\begin{tabular}{lcc}
\hline \multicolumn{1}{c}{ Dataset } & Breast Cancer & Thoracic Surgery \\
\hline Tipe File & DATA & ARFF \\
Banyak Atribut & 9 & 17 \\
Banyak Record & 286 & 470 \\
Karakteristik Atribut & Categorical & Integer, Real \\
Missing Value & Ya & Tidak ada \\
\hline
\end{tabular}

Pada dataset Breast Cancer memiliki 286 baris data dan memliki 9 atribut yaitu; class, age, menopause, tumor-size, inv-nodes, node-caps, deg-malig, breast, breast-quad, irradiat. Dan pada dataset Thoracic Surgery memiliki 470 baris dan 17 atribut diantaranya; DGN, PRE4, PRE5.,PRE6, PRE7, PRE8, PRE9, PRE10, PRE11, PRE14, PRE17, PRE19, PRE25, PRE30, PRE32, AGE, Risk1Yr. Satu kolom kelas berada di awal untuk dataset Breast Cancer dan di akhir pada dataset Thoracic Surgery.

Setelah tahapan proses menggunakan Software Weka, akan menghasilkan output. Gambar 3 adalah contoh hasil pada algoritma Decision Tree-J48 untuk dataset Breast-Cancer

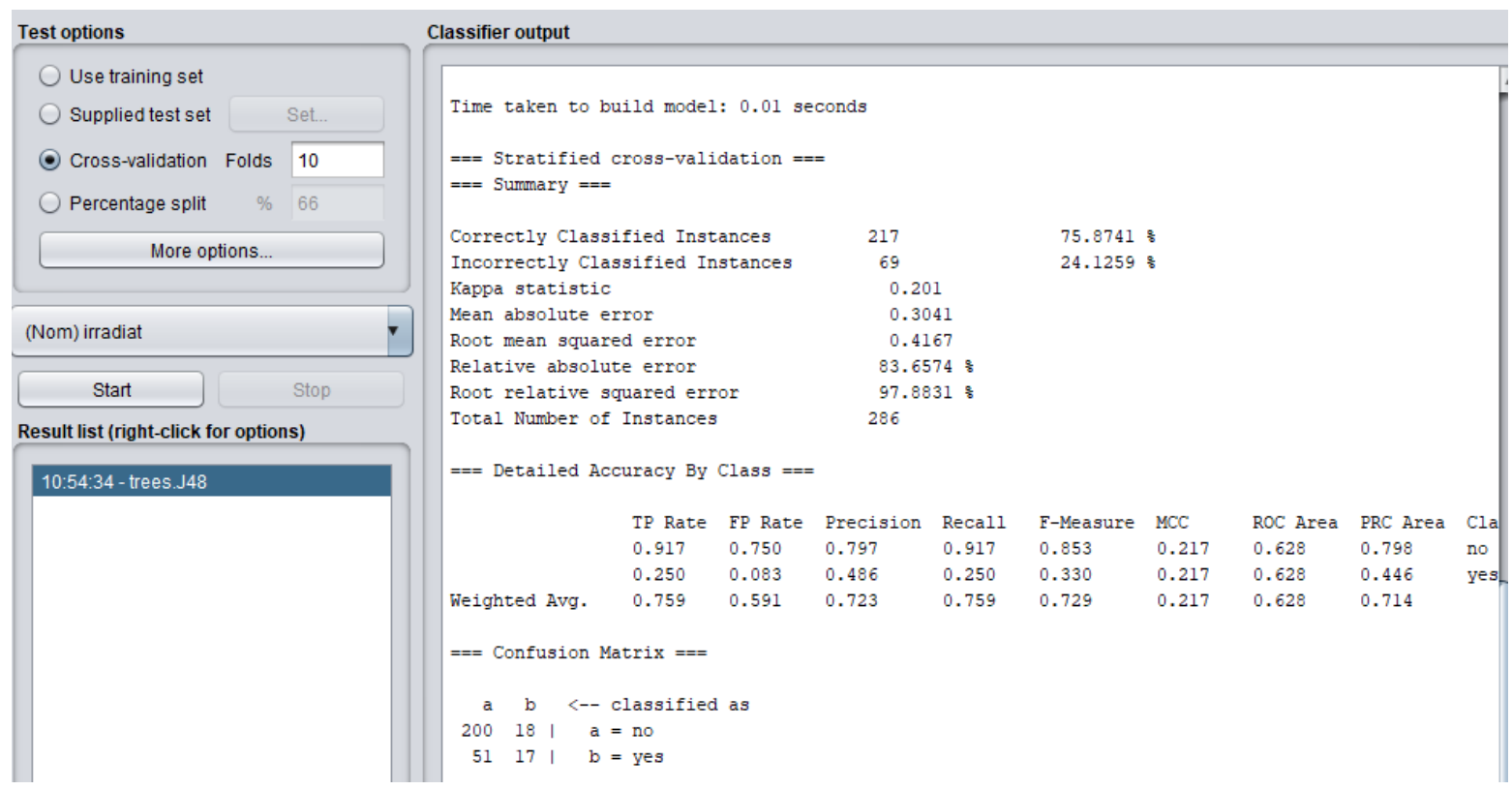

Gambar 3. Hasil Output dari dataset Breast-Cancer

Selanjutnya lakukan berulang menggunakan algoritma yang lain dan dataset Thoracic Surgery. Pada penelitian ini eksperimen dilakukan sekali pada masing-masing dataset, dengan menggunakan mode tes crossvalidation maka dapat dilihat pada tabel 2 untuk hasil kinerja algoritma Naïve Bayes, Lazy-IBK, dan Decision Tree-J48. Informasi akurasi bisa dilihat dari baris correctly classified instances dan incorrectly classified instances.

Tabel 2. Hasil keseluruhan kinerja dari beberapa algoritma

\begin{tabular}{|c|c|c|c|c|c|c|c|}
\hline \multirow[t]{2}{*}{ Dataset } & \multirow[t]{2}{*}{ Algoritma } & \multirow[t]{2}{*}{ Mode Tes } & \multicolumn{2}{|c|}{$\begin{array}{c}\text { Correclty Classified } \\
\text { Instances }\end{array}$} & \multicolumn{2}{|c|}{$\begin{array}{c}\text { Incorreclty Classified } \\
\text { Instances }\end{array}$} & \multirow{2}{*}{$\begin{array}{c}\text { Mean } \\
\text { Absolute } \\
\text { Error }\end{array}$} \\
\hline & & & Jumlah & $\%$ & Jumlah & $\%$ & \\
\hline \multirow{2}{*}{$\begin{array}{l}\text { Breast } \\
\text { Cancer }\end{array}$} & Nä̈ve Bayes & $\begin{array}{c}\text { Cross- } \\
\text { Validation }\end{array}$ & 214 & $74.82 \%$ & 72 & $25.17 \%$ & 0.2777 \\
\hline & $L a z y-I B K$ & $\begin{array}{c}\text { Cross- } \\
\text { Validation }\end{array}$ & 216 & $75.52 \%$ & 70 & $24.47 \%$ & 0.2744 \\
\hline
\end{tabular}




\begin{tabular}{|c|c|c|c|c|c|c|c|}
\hline \multirow[t]{3}{*}{ Dataset } & \multirow[t]{2}{*}{ Algoritma } & \multirow[t]{2}{*}{ Mode Tes } & \multicolumn{2}{|c|}{$\begin{array}{c}\text { Correclty Classified } \\
\text { Instances }\end{array}$} & \multicolumn{2}{|c|}{$\begin{array}{c}\text { Incorreclty Classified } \\
\text { Instances }\end{array}$} & \multirow{2}{*}{$\begin{array}{c}\text { Mean } \\
\text { Absolute } \\
\text { Error }\end{array}$} \\
\hline & & & Jumlah & $\%$ & Jumlah & $\%$ & \\
\hline & $\begin{array}{l}\text { Decision } \\
\text { Tree-J48 }\end{array}$ & $\begin{array}{c}\text { Cross- } \\
\text { Validation }\end{array}$ & 217 & $75.87 \%$ & 69 & $24.12 \%$ & 0.3041 \\
\hline \multirow{3}{*}{$\begin{array}{l}\text { Thoracic } \\
\text { Surgery }\end{array}$} & Nä̈ve Bayes & $\begin{array}{c}\text { Cross- } \\
\text { Validation }\end{array}$ & 369 & $78,51 \%$ & 101 & $21,49 \%$ & 0.2847 \\
\hline & $L a z y-I B K$ & $\begin{array}{c}\text { Cross- } \\
\text { Validation }\end{array}$ & 363 & $77,23 \%$ & 107 & $22,77 \%$ & 0.2289 \\
\hline & $\begin{array}{l}\text { Decision } \\
\text { Tree-J48 }\end{array}$ & $\begin{array}{c}\text { Cross- } \\
\text { Validation }\end{array}$ & 397 & $84,47 \%$ & 73 & $15,53 \%$ & 0.2538 \\
\hline
\end{tabular}

Nilai persentasi pada kolom persen didapatkan dari kolom jumlah dibagi dengan total record dataset dan kemudian dikalikan dengan 100. Secara keseluruhan pada tabel 2, tidak ada yang mencapai $90 \%$ pada kolom Correclty Classified Instances, namun persentase paling tinggi adalah 84,47\% pada algoritma Decision Tree-J48 untuk dataset Thoracic Surgery yaitu dengan total jumlah 397 instances yang terklasifikasi benar dari 470 total data keseluruhan, dan pada kolom mean absolute error adalah 0.2538.

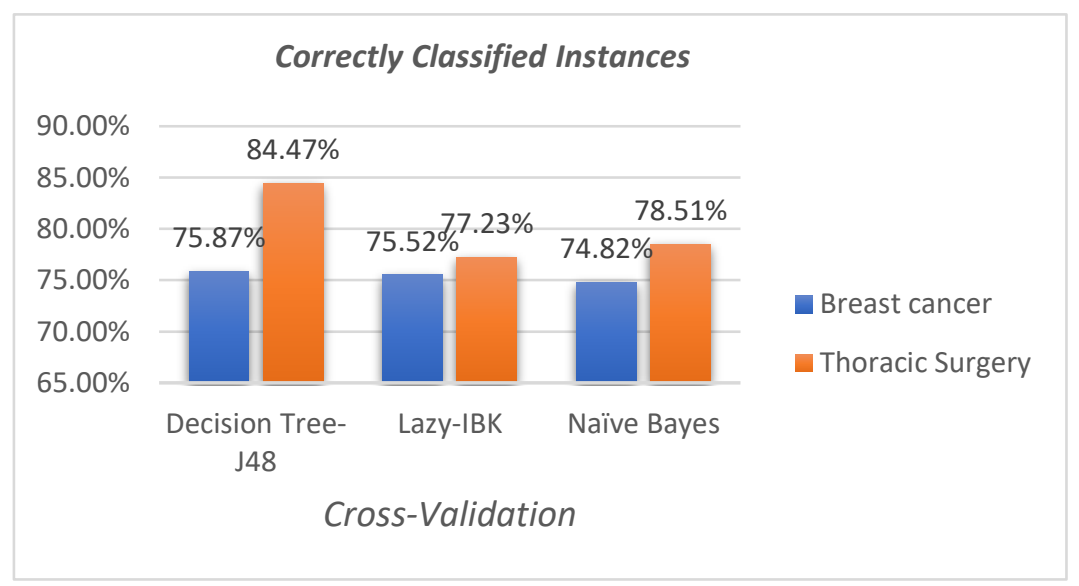

Gambar 4. Hasil perbandingan akurasi klasifikasi data benar

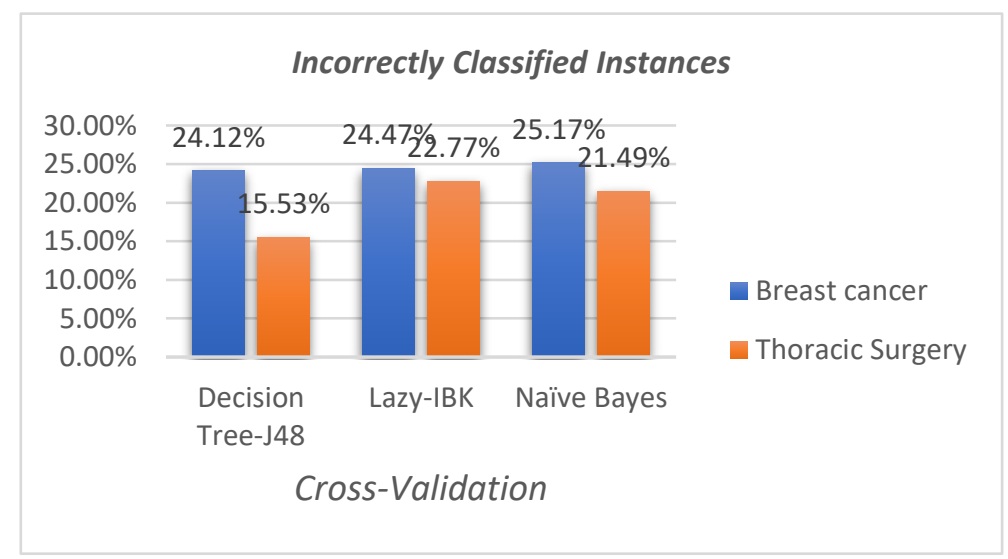

Gambar 5. Hasil perbandingan akurasi klasifikasi data salah 
Dari dua grafik yang tertera pada gambar 4 dan gambar 5 memperlihatkan perbandingan nilai akurasi dari beberapa algoritma yang digunakan untuk mengolah data Breast Cancer dan Thoracic Surgery. Pada gambar 4 terlihat bahwa Decision Tree-J48 mendapatkan hasil akurasi paling tinggi dibanding algoritma yang lain, untuk dataset Breast Cancer maupun Thoracic Surgery. Sedangkan pada gambar 5 memperlihatkan data yang terklasifikasi salah pada algoritma Decision Tree-J48 memiliki nilai paling kecil diantara algoritma yang lain

Tabel 3. Waktu (detik) yang dibutuhkan untuk membangun model

\begin{tabular}{cccc}
\hline Mode Tes & Algoritma & Breast Cancer & Thoracic Surgery \\
\hline Cross & Nä̈ve Bayes & 0 & 0 \\
Validation & Lazy-IBK & 0 & 0 \\
& Decision Tree-J48 & 0.01 & 0.01 \\
\hline
\end{tabular}

Dari data tabel 3 dapat diketahui informasi mengenai waktu yang dibutuhkan untuk membangun model pada beberapa algoritma klasifikasi. Meskipun perbedaan waktu antara algoritma tidak terlalu signifikan. Gambar 6 adalah salah satu contoh output hasil generate untuk algoritma Decision Tree-J48 menggunakan mode tes crossvalidation. Output tersebut memperlihatkan hasil waktu yang dibutuhkan untuk membangun model klasifikasi yaitu 0.1 detik.

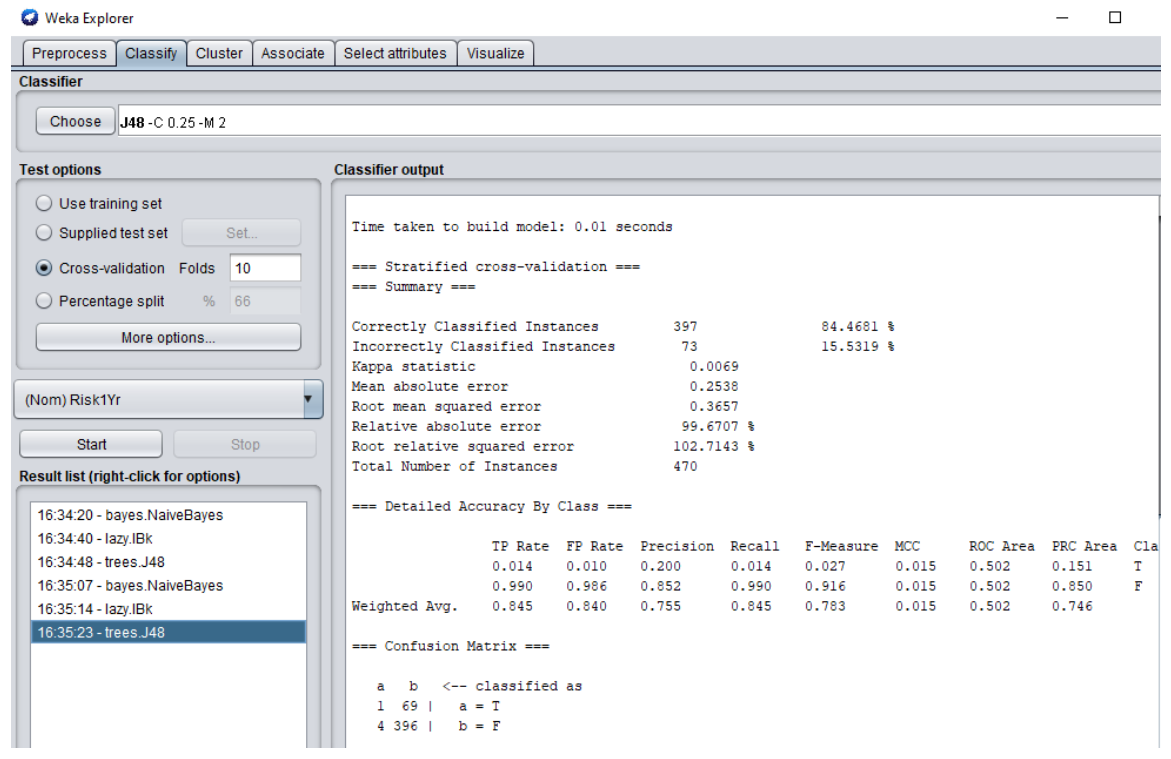

Gambar 6. Hasil generate waktu pada saat membangun model

\section{KESIMPULAN}

Hasil dari kinerja algoritma Nä̈ve Bayes, Lazy-BK, Decision Tree-J48 dapat disimpulkan bahwa algoritma Decision Tree-J48 memiliki kinerja akurasi yang sangat tinggi dibandingkan dengan algoritma lain. Hal tersebut dapat dibuktikan pada Correctly Classified Instances pada dataset Thoracic Surgery mencapai $84.47 \%$ pada mode tes cross-validation. Meskipun waktu generate berbeda 0.1 detik karena tidak terlalu signifikan

\section{UCAPAN TERIMAKASIH}

Peneliti mengucapkan terima kasih kepada Ibu Fitriyani, S.T., M.Kom selaku dosen pembimbing yang telah memberikan bimbingan, arahan kepada peneliti. Serta mengucapkan kepada Matjaz Zwitter, Milan Soklic dan Marek Lubicz, Konrad Pawelczyk, Adam Rzechonek, Jerzy Kolodziej atas dataset Breast Cancer dan Thoracic Surgery di UCI Repository.

\section{REFERENCES}

[1] F. Ma'arif and T. Arifin, "Optimasi Fitur Menggunakan Backward Elimination Dan Algoritma SVM Untuk Klasifikasi Kanker Payudara," J. Inform., vol. 4, no. 1, pp. 46-53, 2017.

[2] A. Handayani, A. Jamal, and A. A. Septiandri, “350-565-1-Sm,” vol. 6, no. 4, pp. 394-403, 2017.

[3] Y. A. Setyadi, I. Asror, Y. Firdaus, and A. Wibowo, "Prediksi Harapan Hidup Pasca Operasi Toraks pada Pasien Penderita Kanker Paru-paru Menggunakan Metode Genetic Algorithm untuk Feature Selection dan Naïve Bayes Classifier," vol. 7, no. 2, pp. 8349-8360, 2020.

[4] I. F. Anshori and D. Riana, "Prediksi Harapan Hidup Pasien Kanker Paru-Paru Pasca Operasi Bedah Thoraks 
Menggunakan Boosted Neural Network Dan Smote,” vol. 6, no. 1, pp. 9-15, 2021.

[5] I. K. Juni Arta, G. Indrawan, and G. R. Dantes, "Data Mining Rekomendasi Calon Mahasiswa Berprestasi Di Stmik Denpasar Menggunakan Metode Technique for Others Reference By Similarity To Ideal Solution,” JST (Jurnal Sains dan Teknol., vol. 5, no. 2, p. 792, 2017, doi: 10.23887/jst-undiksha.v5i2.8549.

[6] P. Analisa, D. A. N. Klasifikasi, C. Di, A. Rifa, G. G. Setiaji, and V. Vydia, "PENGGUNAAN METODE K-MEANS Fakultas Teknologi Informasi dan Komunikasi, Universitas Semarang,” vol. 15, no. 1, pp. 43-47, 2019.

[7] D. Sartika and D. Indra, "Perbandingan Algoritma Klasifikasi Naive Bayes, Nearest Neighbour, dan Decision Tree pada Studi Kasus Pengambilan Keputusan Pemilihan Pola Pakaian,” J. Tek. Inform. Dan Sist. Inf., vol. 1, no. 2, pp. 151-161, 2017.

[8] A. R. Kadafi, "Perbandingan Algoritma Klasifikasi Untuk Penjurusan Siswa SMA," J. ELTIKOM, vol. 2, no. 2, pp. 6777, 2018, doi: 10.31961/eltikom.v2i2.86.

[9] N. A. Setifani, D. N. Fitriana, and A. Yusuf, "Perbandingan Algoritma Naïve Bayes, Svm, Dan Decision Tree Untuk Klasifikasi Sms Spam,” JUSIM (Jurnal Sist. Inf. Musirawas), vol. 5, no. 02, pp. 153-160, 2020, doi: 10.32767/jusim.v5i02.956.

[10] D. Yunita, "Perbandingan Algoritma K-Nearest Neighbor dan Decision Tree untuk Penentuan Risiko Kredit Kepemilikan Mobil," J. Inform. Univ. Pamulang, vol. 2, no. 2, p. 103, 2017, doi: 10.32493/informatika.v2i2.1512.

[11] Ardiyansyah, P. A. Rahayuningsih, and R. Maulana, "Analisis Perbandingan Algoritma Klasifikasi Data Mining Untuk Dataset Blogger Dengan Rapid Miner," J. Khatulistiwa Inform., vol. VI, no. 1, pp. 20-28, 2018.

[12] P. D. Putra and D. P. Rini, "Prediksi Penyakit Jantung dengan Algoritma Klasifikasi," Pros. Annu. Res. Semin. 2019 , vol. 5, no. 1, pp. 978-979, 2019.

[13] P. Kasih, "Pemodelan Data Mining Decision Tree Dengan Classification Error Untuk Seleksi Calon Anggota Tim Paduan Suara," Innov. Res. Informatics, vol. 1, no. 2, pp. 63-69, 2019, doi: 10.37058/innovatics.v1i2.918.

[14] D. Noviana, Y. Susanti, and I. Susanto, "Analisis Rekomendasi Penerima Beasiswa Menggunakan Algoritma K-Nearest Neighbor (K-NN) dan Algoritma C4.5,”Semin. Nas. Penelit. Pendidik. Mat. 2019 UMT, pp. 79-87, 2019.

[15] I. Mubarog, A. Setyanto, and H. Sismoro, "Sistem Klasifikasi Pada Penyakit Breast Cancer Dengan Menggunakan Metode Naïve Bayes," Creat. Inf. Technol. J., vol. 6, no. 2, p. 109, 2021, doi: 10.24076/citec.2019v6i2.246.

[16] I. A. Nikmatun and I. Waspada, "Implementasi Data Mining untuk Klasifikasi Masa Studi Mahasiswa Menggunakan Algoritma K-Nearest Neighbor,” J. SIMETRIS, vol. 10, no. 2, pp. 421-432, 2019.

[17] D. A. Adeniyi, Z. Wei, and Y. Yongquan, "Automated web usage data mining and recommendation system using KNearest Neighbor (KNN) classification method," Appl. Comput. Informatics, vol. 12, no. 1, pp. 90-108, 2016, doi: 10.1016/j.aci.2014.10.001. 